\title{
CONTEMPORÂNEO CLÁSSICO: A RECEPÇÃO DE PIERRE BOURDIEU NO BRASIL*
}

\author{
José Henrique Bortoluci, Luiz C. Jackson \\ e Fernando A. Pinheiro Filho
}

O Brasil foi um dos países pioneiros na recepção internacional de Pierre Bourdieu, tornando-se progressivamente um de seus casos principais (Sapiro e Bustamante, 2009). Na última década, o autor tornou-se certamente o sociólogo mais citado e influente no país ${ }^{1}$.

Um estudo sobre a recepção de sua obra nesse caso deve levar em conta, antes de tudo, que tal processo se dá

\footnotetext{
* Este artigo é uma versão de um capítulo que será publicado em obra coletiva organizada pelos sociólogos George Steinmetz (University of Michigan), Marco Santoro (Universidade de Bologna) e Gisèle Sapiro (École des Hautes Études en Sciences Sociales - EHESS). O texto expande e aprofunda um trabalho anterior de um dos autores (cf. Pinheiro Filho, 2009).

1 Alguns parâmetros relativos a meados de 2012 são suficientes para comprovar essa afirmação. Consultado o sistema Lattes - a principal base de currículos de acadêmicos brasileiros, composto pela quase totalidade desses documentos -, constata-se que Bourdieu é o terceiro autor contemporâneo das ciências sociais e humanas mais citado (766 ocorrências), atrás apenas de Foucault (1941) e Habermas (1035). $\mathrm{Na}$ área de sociologia, Bourdieu é o mais citado (310 referências). Na base de dados Scielo, a principal para revistas acadêmicas brasileiros, Bourdieu é o segundo autor contemporâneo mais citado (184 artigos), atrás apenas de Foucault (349 artigos). Um dado adicional para a área de sociologia refere-se ao fato de Bourdieu ser o autor contemporâneo mais citado em um livro recente de entrevistas com os principais sociólogos brasileiros (Bastos et al. 2006).
} 
por meio de relações assimétricas entre um sistema intelectual periférico e um centro produtor da sociologia, e que a tradição francesa desempenhou papel central na constituição das humanidades no Brasil, desde ao menos o século XIX. Visando evitar possíveis anacronismos, trataremos dessa questão articulando duas séries históricas: a produção e consagração da obra de Bourdieu a partir da França e a dinâmica da institucionalização das ciências sociais no Brasil.

No Brasil, a institucionalização das ciências sociais pode ser dividida em três fases: fundação, expansão e especialização (Jackson e Blanco, 2014). Na primeira, delimitada pela Revolução de 1930 e o Golpe Militar de 1964, surgem as primeiras instituições acadêmicas envolvidas com ensino e a pesquisa de tais disciplinas, são criados órgãos especializados (editoras e periódicos) de difusão dos trabalhos realizados e inicia-se a profissionalização do cientista social como produtor intelectual. Nessa fase, a sociologia prevalece claramente 218 sobre as outras duas disciplinas (antropologia e ciência política), constituindo-se como núcleo dos cursos de graduação criados no período. As pesquisas empreendidas são orientadas em geral por temas amplos ligados ao processo de modernização do país, e, portanto, condicionados pela dinâmica política abrangente. Na segunda fase de expansão, entre 1964 e a abertura democrática ocorrida em 1985, as ciências sociais ganham maior presença no sistema de educação superior nacional, institucionalizando-se propriamente, tanto por meio da nacionalização do sistema universitário (criação das universidades federais), como da pós-graduação em seu interior. Inúmeros cursos de graduação são criados; a antropologia e a ciência política se fortalecem, equiparando-se à sociologia. Nesse período, incrementa-se um processo de especialização, mas a maioria dos trabalhos converge para o entendimento das questões ligadas à democratização e às relações entre Estado e sociedade (Keinert, 2011). Consolidada a transição democrática em 1985, inicia-se uma terceira fase, na qual o processo de especialização 
avança muito em relação à anterior, havendo maior dispersão teórica e temática no interior de cada uma das disciplinas. $\mathrm{O}$ horizonte das pesquisas se distancia da arena política, ocorrendo a plena profissionalização das três disciplinas.

Neste artigo, discutiremos a difusão da obra de Bourdieu no Brasil em cada uma das fases mencionadas, cuidando do debate gerado por seus textos, à medida que se dá a efetiva incorporação de seu pensamento às pesquisas no campo das ciências humanas - sobretudo na sociologia, disciplina na qual se tornou referência incontornável -, além de assinalar o influxo renovador de sua presença na vida intelectual brasileira em geral.

Mais especificamente, tentaremos responder duas questões relacionadas à recepção de dois livros fundamentais de Bourdieu: 1) por que $A$ distinção teve uma recepção tardia e relativamente limitada no Brasile; 2) como As regras da arte tornou-se a mais influente obra de Bourdieu publicada em nosso país? Secundariamente, tentaremos interpretar a recepção inicial de Bourdieu como um conservador no âmbito dos estudos educacionais e tratar da polêmica decorrente da publicação, em 2002, de "Sobre as artimanhas da razão imperialista”, de Bourdieu e Loïc Wacquant, entre os estudiosos das relações raciais no país.

Como hipótese geral, sugerimos neste texto que a recepção de Bourdieu se deu a partir das margens do sistema acadêmico, especialmente nas ciências sociais, desde o final dos anos de 1960, quando a circulação de pesquisadores brasileiros no exterior implicou uma renovação teórica de tais disciplinas. Mobilizado inicialmente na área de estudos rurais, sua obra consolidou-se posteriormente como referência central, sobretudo no domínio da sociologia da cultura.

\section{Antes de Bourdieu - a fundação da sociologia no Brasil}

A rigor, a incorporação da obra de Bourdieu no Brasil inicia-se na segunda fase do esquema que acabamos de propor, 
se tomamos como referência a publicação de seu primeiro texto no país, "Campo intelectual e projeto criador", artigo de 1966, que havia saído no número 246 da revista Les Temps Modernes, editado no Brasil como livro em 1968, com o título Problemas do estruturalismo. Essa foi uma iniciativa do antropólogo Moacir Palmeira, pioneiro na introdução do sociólogo francês no país, que seguira os seminários de Bourdieu na École des Hautes Études en Sciences Sociales entre 1966 e 1969. Essa circunstância relaciona-se com a circulação crescente de pesquisadores brasileiros na Europa e nos Estados Unidos nesse momento, e veremos adiante que as primeiras incorporações de sua obra relacionam-se diretamente a esse movimento (cf. Lopes, 2013).

Certas características ligadas à fase de fundação da sociologia no Brasil condicionaram a recepção futura de Bourdieu - razão pela qual faremos um recuo até esta primeira fase. Se a obra de Bourdieu faz profissão de fé na 220 cientificidade da sociologia e ocupa-se com especial interesse da esfera cultural, temos aqui dois aspectos em consonância com projetos acadêmicos construídos nessa fase concentrada nos estados de São Paulo e Rio de Janeiro.

No Rio de Janeiro, centro da vida política brasileira na primeira metade do século XX, as ciências sociais foram diretamente condicionadas pelas disputas políticas e ideológicas que marcaram o período getulista. Pode-se afirmar que uma das marcas da sociologia carioca seja um comprometimento político mais direto do que o da sociologia paulista. Não existia na então capital federal vida acadêmica autônoma: praticamente não havia pesquisa na Universidade do Brasil (criada em 1939); tal atividade concentrava-se em institutos desvinculados da estrutura acadêmica oficial, sobretudo no Instituto Superior de Estudos Brasileiros (Iseb) ${ }^{2}$.

2 Sobre a história das ciências sociais no Rio de Janeiro, ver principalmente Miceli (1989), Almeida (1987), Oliveira (1995), Vianna (2004) e Lima (1999). 
Em São Paulo, o arranjo histórico dado pela supremacia econômica do Estado - impulsionada pela economia do café, pelo processo de industrialização e crescimento dos centros urbanos nas primeiras três décadas do século XX -, bem como pelas derrotas políticas sofridas em 1930 e 1932 possibilitou o investimento político na reforma educacional, que teve como pilar a criação da Universidade de São Paulo (USP) em 1934 e, nela, da Faculdade de Filosofia, Ciências e Letras (FFCL). Também a criação da Escola Livre de Sociologia e Política de São Paulo (ELSP) em 1933 resultou desse contexto. Imaginavam os mentores das duas escolas que as elites nelas formadas constituiriam quadros políticos e técnicos envolvidos na retomada da hegemonia política do país por São Paulo. No entanto, ambos os cursos orientaram-se por objetivos predominantemente acadêmicos, o que implicou o desenvolvimento na metrópole paulistana de uma vida universitária mais autônoma e, assim, mais comprometida com valores científicos.

Com a chegada do norte-americano Donald Pierson (que fora aluno de Robert Park em Chicago) a São Paulo em 1939, para assumir a direção da ELSP, prevaleceu o intuito de constituir um novo padrão de produção intelectual, marcado pela cientificidade e pelo profissionalismo. Entretanto, seria a presença de professores franceses na USP o fato responsável pela consolidação da sociologia como disciplina moderna e dominante entre as ciências humanas até o final da década de 1960 no Brasil. A figura mais destacada da missão francesa foi, provavelmente, Roger Bastide, apesar da consagração posterior incomparável de outros professores que dela participaram, como Claude Lévi-Strauss e Fernand Braudel. Roger Bastide viveu em São Paulo entre 1938 e 1954 e empenhou-se pelo estabelecimento de uma sociologia da cultura - que, de certa forma, antecipou a direção analítica perseguida por Bourdieu décadas mais tarde (Heinich, 2001) -, a partir da qual os 
processos de "interpenetração de civilizações" poderiam ser analisados em função da modernização em curso acelerado do Brasil da metade do século XX (Peixoto, 2000). Estudos sobre folclore, religião, arte, literatura foram realizados por Bastide e seus alunos. Indiretamente, o desdobramento mais consagrado desse programa seria levado a cabo por Antonio Candido no âmbito da crítica literária (Jackson e Blanco, 2014). Com o retorno de Bastide à França, a sociologia da cultura perderia espaço para a sociologia do desenvolvimento encampada por Florestan Fernandes e seu grupo, interessada em reconstituir a especificidade do processo de desenvolvimento capitalista e de formação da sociedade de classes no país.

Em São Paulo, os esforços de Donald Pierson e Florestan Fernandes em estabelecer a sociologia como uma disciplina científica e a defesa da sociologia da cultura por Bastide criaram condições favoráveis à recepção posterior

222 da obra de Bourdieu. Além disso, a importância da missão francesa na fundação da sociologia brasileira favoreceu a continuidade da influência dessa tradição intelectual no país e, portanto, a incorporação de autores franceses nas décadas seguintes. Mais especificamente, vale a pena mencionar que a rede de contatos criada por Bastide no final da década de 1950, para receber alguns pesquisadores brasileiros na França e reforçada por sua discípula brasileira Maria Isaura Pereira de Queiroz, seria acionada nas duas décadas seguintes por jovens cientistas sociais que se relacionariam direta ou indiretamente com o grupo de Bourdieu, como alguns dos que mencionaremos a seguir.

\section{Expansão das ciências sociais no Brasil e primeira recepção de Bourdieu}

Com o golpe militar de 1964, dá-se uma reestruturação do sistema de educação superior no Brasil, que seria unificado nesse período com a criação de inúmeras universidades 
federais. Nas ciências sociais, além da multiplicação dos cursos de graduação pelo país, ocorre um crescimento notável da pós-graduação, favorecida pelas políticas de financiamento público e privado, paradoxalmente adotadas pelo mesmo governo que interrompeu compulsoriamente carreiras de intelectuais destacados - como foi o caso, na Universidade de São Paulo, dos sociólogos Florestan Fernandes, Fernando Henrique Cardoso e Octávio Ianni, da cientista política Paula Beiguelman e do filósofo Bento Prado Jr. (Ortiz, 1990). Mais especificamente, foram inaugurados os Programas de Pós-Graduação em Antropologia Social do Museu Nacional e de Ciência Política no Iuperj, ambos no Rio de Janeiro em 1969, que se converteriam nos centros dominantes dessas disciplinas no país. Resulta disso um descentramento em relação à sociologia e a São Paulo, em favor de um novo arranjo ecológico que beneficiou os estados do Rio de Janeiro e de Minas Gerais, entre outros, e dinamizou o desenvolvimento da antropologia e da ciência política. Na USP, a sociologia permaneceria como disciplina dominante, embora atravessando uma crise profunda, decorrente tanto das perseguições sofridas e da reorganização de seu corpo docente, como da reforma universitária dos fins da década de 1960, que instituiu os departamentos e eliminou as cátedras (Leite, 2014). Nesse contexto, o marxismo tornou-se o paradigma teórico dominante na sociologia paulista, dificultando a incorporação de perspectivas teóricas contemporâneas não diretamente afinadas com ele ${ }^{3}$.

O efeito mais direto dessa nova configuração para a entrada efetiva de Bourdieu no Brasil ligou-se à circulação internacional de jovens pesquisadores brasileiros, incrementada nesse momento e estimulada pela concessão de bolsas de estudo e pelo novo padrão de profissionalização

\footnotetext{
3 Esse diagnóstico a respeito da resistência oferecida pela sociologia uspiana às tentativas de renovação teórica nos anos de 1970 veio à tona na maioria das entrevistas que realizamos para este trabalho.
} 
em curso. Esses cientistas sociais, então em início de carreira, atuariam como mediadores na renovação de tais disciplinas ao introduzirem novos autores e perspectivas no debate teórico em curso ${ }^{4}$. Alguns deles incorporaram os instrumentos de análise bourdiesianos em seus trabalhos e, ao mesmo tempo, empenharam-se na publicação dos primeiros textos do autor no Brasil ${ }^{5}$. Desse movimento resultou uma rede de sociabilidade e colaboração - mesmo que assimétrica e restrita - entre cientistas sociais brasileiros e o grupo de Bourdieu, que se mantém ativa até os dias atuais e que direcionou em grande medida essa recepção ${ }^{6}$.

O conjunto das publicações brasileiras de Bourdieu no período é uma fração bastante reduzida de sua produção na França, o que revela o caráter limitado e circunstancial desse esforço editorial. Outro aspecto a ser destacado diz respeito à assimilação desigual desses textos pela comunidade acadêmica: as publicações mais influentes 224 nesse momento foram coletâneas organizadas por mediadores brasileiros (Bourdieu, 1974 e 1983). Antes disso, o primeiro texto publicado é o já mencionado "Campo inte-

\footnotetext{
4 Sobre os mediadores, vale ressaltar que ocorrem até hoje disputas pela centralidade e/ou especificidade dos papéis desempenhados por cada um deles nesse processo. Em texto recente, José Sérgio Leite Lopes (2013) sublinha a importância desses agentes, com especial atenção ao caso do Museu Nacional, em que ele foi um dos protagonistas.

5 Ver bibliografia, ao final deste artigo, para a ordem das traduções das obras de Bourdieu no Brasil em cada uma das fases descritas.

6 Até onde sabemos, esse contato mais estreito e prolongado de pesquisadores brasileiros com o grupo de Bourdieu não se deu com pesquisadores de outros países da América Latina com a mesma importância. Essa troca constante pode ser verificada pela publicação de artigos de acadêmicos brasileiros na Actes de la Recherche en Sciences Sociales (Miceli, 1975 e 2007; Loyola, 1982; Garcia Jr., 1986, 1993, 1998 e 2011; Rodrigues, 1988; Lopes e Maresca, 1989; Lopes e Alvim, 1990; Lopes e Faguer, 1994; Durand, 1991; Loureiro, 1995 e 1998; Vasconcellos, 1998), de acadêmicos franceses ligados a Bourdieu em revistas brasileiras (por exemplo, Pinto, 2009; Sapiro, 2004; Delsaut, 2005; Wacquant, 1997 e 2006), pelas posições ocupadas por brasileiros no interior das instituições do sistema acadêmico francês controladas pelos bourdiesianos e, finalmente, pela circulação frequente de brasileiros nessas instituições (sobretudo o Centre de Sociologie Européenne) em estágios de pesquisa.
} 
lectual e projeto criador" (de 1968), que, por reivindicar para a sociologia um papel central na análise da cultura, impactaria diretamente os principais sociólogos da cultura nas décadas seguintes ${ }^{7}$.

Moacir Palmeira sugeriu à editora Zahar a publicação do número da revista Temps Modernes que continha o texto "Campo intelectual e projeto criador". Ele foi responsável, ainda, pela primeira utilização direta da teoria bourdiesiana por um cientista social brasileiro. Isso ocorreu em sua tese de doutoramento defendida em Paris no ano de 1971, Latifúndio et capitalisme au Brésil: lecture critique d'un débat. $\mathrm{O}$ trabalho reconstitui o debate a respeito da existência ou não do feudalismo no Brasil. Para cumprir tal percurso, foi decisivo o uso direto da noção de "campo" na análise desenvolvida pelo autor, no momento em que Bourdieu e seus alunos elaboravam seus primeiros estudos sobre diferentes setores do campo intelectual francês (Palmeira, 1971). A tese teve o mérito de incorporar reflexividade a esse tipo de estudo, por recusar o viés puramente intelectual de uma querela travada entre especialistas armados de seus saberes específicos sobre a existência do modo de produção feudal, revelando sua dimensão política e seu condicionamento pelo meio intelectual em questão.

A circulação da tese de Moacir Palmeira no Brasil foi restringida pelo fato de jamais haver sido publicada em livro. Ainda assim, a partir de seu retorno ao país, os trabalhos de Bourdieu passaram a difundir-se entre seus colegas e alunos do Programa de Pós-Graduação em Antropologia Social do Museu Nacional. De acordo com o depoimento do autor, sua experiência na França e sua interlocução direta com Bourdieu o teriam incentivado a trabalhar em equipe ${ }^{8}$,

\footnotetext{
7 Em depoimento aos autores, Sérgio Miceli e Maria Arminda do Nascimento Arruda, figuras centrais no desenvolvimento da sociologia da cultura na USP, por exemplo, o qualificam como um texto seminal.

8 Ainda em seu depoimento, Palmeira se referiu à defesa que Bourdieu teria feito para ele do trabalho coletivo como uma espécie de antídoto contra a fragmentação
} 
o que ocorreria, sobretudo, no projeto "Estudo comparado do desenvolvimento regional", que produziu etnografias importantes a respeito das transformações do mundo rural brasileiro, e que, de início centrado no trabalho agrícola, passa a abranger as camadas de trabalhadores urbanos e o operariado industrial (Lopes, 1976; Sigaud, 1979; Garcia Jr., 1983). De acordo com José Sérgio Leite Lopes (2003 e 2013), ele mesmo parte da equipe que contava também com, entre outros, Lygia Sigaud e Afrânio Garcia, além do próprio Palmeira, os produtos surgidos a partir dessa iniciativa ao longo dos anos de 1970, em que Bourdieu era uma das referências centrais, ultrapassaram a reconstrução dos mecanismos de exploração a que esses grupos estavam sujeitos, evidenciando as modalidades de interiorização da dominação pelos próprios dominados. Note-se que, nesse momento, Bourdieu é mobilizado como instrumento para pensar o conflito político - um traço marcante da recepção 226 carioca, em contraste com a paulista.

Assim, a primeira incorporação da obra de Bourdieu no Brasil não se deu na sociologia paulista, dominante até então, mas a partir de um novo programa de pós-graduação (Museu Nacional - RJ) e de uma disciplina (antropologia), que nesse momento ascendiam e se institucionalizavam no panorama das ciências sociais brasileiras ${ }^{9}$.

Outro personagem diretamente associado à aclimatação de Bourdieu no Brasil - provavelmente o principal mediador desse processo - foi o sociólogo Sergio Miceli. Formado em ciências sociais pela Pontifícia Universidade Católica do Rio de Janeiro (PUC-Rio), Miceli ingressou

do campo acadêmico, permitindo a formação de um espaço de interlocução - o que fazia todo sentido nesse momento em que novas instituições acadêmicas se estabeleciam no Brasil, como o Museu Nacional.

9 Se a antropologia foi a porta de entrada para Bourdieu no país e um dos meios principais de sua divulgação até os dias atuais, o autor nunca se tornou uma referência teórica dominante nessa disciplina - como ocorreria posteriormente na sociologia. 
na pós-graduação da USP no final da década de 1960. Seu ingresso como professor nessa universidade, entretanto, foi relativamente tardio (1989), o que permitiu a ele contornar a resistência à inovação teórica que tinha lugar nessa instituição nas décadas de 1970 e 1980 . Nesse período, Miceli lecionou na Fundação Getúlio Vargas (FGV). Esse aspecto de sua carreira reforça nossa hipótese de que a entrada de Bourdieu se deu pelas margens do sistema de ensino e pesquisa em ciências sociais.

Já em sua dissertação de mestrado, uma análise de um programa televisivo popular (Miceli, 1972), o autor compôs o esquema interpretativo do trabalho combinando a sociologia de Bourdieu com a semiótica e, secundariamente, com a teoria crítica frankfurtiana, então referência central para a sociologia da cultura que lentamente voltava a ganhar fôlego no país. De acordo com o relato do autor, a geração de sociólogos com interesse pela área - que, no país, incluiria estudos sociológicos sobre arte, intelectuais e indústria cultural - via-se naquele momento relativamente deslocada, uma vez que tais temas eram pouco valorizados pela sociologia brasileira de então, e a alternativa disponível não contemplava o interesse propriamente sociológico, concentrando-se na crítica cultural, área centralizada na perspectiva desenvolvida por Antonio Candido e seu grupo na USP ${ }^{10}$. Nesse contexto adverso, a obra de Bourdieu seria mobilizada por alguns jovens sociólogos que encontram nela a

\footnotetext{
${ }^{10}$ Embora a crítica literária desenvolvida pelo grupo tenha uma inclinação sociológica, ela supõe a "autonomia relativa" do texto literário e entende a sociologia apenas como uma disciplina auxiliar para a análise dos textos. Vale lembrar que, ainda na USP, o sociólogo Gabriel Cohn liderava então uma aposta na teoria frankfurtiana como um ponto de fuga aos esquemas mais endurecidos do marxismo estruturalista - conforme entrevista concedida pela socióloga Maria Arminda do Nascimento Arruda, ela mesma influenciada à época por essa vertente teórica. Havia ainda uma terceira vertente de estudos da cultura liderada pelo sociólogo Ruy Coelho que, apesar de deslocado na sociologia uspiana de então, orientou diversos trabalhos nesse momento.
} 
legitimidade científica ${ }^{11}$ para o enfrentamento da resistência acadêmica aos objetos não diretamente relacionados à sociologia política que então predominava.

No período em questão, Sergio Miceli cumpriu papel decisivo ao editar uma das primeiras coletâneas de Pierre Bourdieu publicadas no mundo (Bourdieu, 1974) e que teria grande ressonância no Brasil, não apenas pelos textos coligidos ${ }^{12}$, mas também pela apresentação escrita pelo organizador, que se tornaria uma espécie de guia de leitura para esse conjunto de textos - e, por extensão, para a obra -, com o condão de apresentar a novidade produzida no centro de modo a fazer sentido num sistema intelectual periférico $^{13}$. Essa iniciativa seria decisiva para a carreira do sociólogo brasileiro, por colocá-lo em contato direto com Bourdieu, que, a partir de então, tornar-se-ia uma referência intelectual prioritária para Miceli e, por meio deste último, para a sociologia da cultura brasileira a partir dos anos 228 de 1990.

Intitulado "A força do sentido", o ensaio de Miceli procura extrair os conceitos formulados por Bourdieu da discussão dos impasses a que chegaram as linhas mais relevantes da teoria sociológica moderna a partir de seu fundamento nos autores clássicos da disciplina. Assim, não só

${ }^{11} \mathrm{O}$ fato de Bourdieu ser um acadêmico francês certamente favoreceu a sua paulatina aceitação em um ambiente acadêmico como o brasileiro - e paulista em particular -, em que, como vimos, a tradição francesa sempre foi dominante.

${ }_{12}$ Nessa coletânea foram publicados os textos "O mercado dos bens simbólicos" e "Campo do poder, campo intelectual e habitus de classe", que, de acordo com Louis Pinto, complementaram na França, em continuidade ao texto "Campo intelectual e projeto criador", uma espécie de "...primeiro programa de análises" (Pinto, 2000, p. 69) em sociologia da literatura. Esse programa desembocaria mais tarde n'As regras da arte e nos trabalhos desenvolvidos no centro sob a orientação direta ou indireta de Bourdieu, como os de Cristophe Charle, Alain Viala, Anna Boschetti, Gisèle Sapiro e Pascale Casanova.

${ }^{13} \mathrm{O}$ volume compreendia artigos publicados originariamente entre 1966 e 1971 e tratava de temas como religião, educação e o sistema de produção de bens culturais. O organizador realizou a maior parte das traduções e o editou consultando diretamente o autor. 
organiza o debate no interior das frentes estruturalistas remetendo-as a Durkheim e Marx como, com base nisso, faz surgir a ligação entre as noções de campo e habitus como alternativa para uma saída possível da oposição entre formas de explicação centradas ou na ação ou na estrutura, quando pensadas como alternativas excludentes. Aliado a esse trabalho preliminar, o texto explora os paralelos e diferenças entre as teorias da dominação de Weber e Bourdieu. Como resultado, lança luz sobre um dos focos centrais da empresa de Bourdieu, qual seja, o de pensar os sistemas simbólicos em sua inteireza, sem dissociar suas funções de comunicação e dominação, ressaltando assim a base argumentativa que permite entender as conversões dissimuladas da força em sentido, da violência aberta em "violência simbólica". Essa estratégia de exposição logrou construir novos nexos na discussão então em voga no meio acadêmico brasileiro, que mobilizava, entre outras, a corrente althusseriana, a fenomenologia e o estruturalismo de Lévi-Strauss.

Orientado formalmente por Bourdieu em Paris, Miceli publicou em 1979 sua tese de doutorado, Intelectuais e classe dirigente no Brasil (1920-1945) ${ }^{14}$, que, enfocando a trajetória intelectual de escritores do período, expõe sua relação com as elites dirigentes, central para a progressão de suas carreiras em geral marcadas no ponto de início pela herança negativa do declínio social e econômico de suas famílias (Miceli, 1979). O livro constitui um modo inovador de enraizar socialmente uma atividade que se representa como assentada apenas em imperativos imanentes, dando relevo a detalhes significativos como os estigmas corporais e as relações de gênero, entre outros recursos de construção dos agentes. Merece destaque o fato de a análise, acompanhada de perto por Bourdieu, prescindir do uso da noção de campo. Assim, Miceli retém a preocupação nuclear da sociologia

${ }^{14}$ Sobre o impacto e os desafios analíticos dessa obra, ver Bastos e Botelho (2010). 
de Bourdieu de encontrar os ligamentos entre as práticas e suas circunstâncias, mas busca para ela uma solução atenta às condições históricas específicas com que lida ${ }^{15}$. $\mathrm{O}$ autor entende o livro como uma espécie de súmula metodológica de tudo que realizaria depois, como os estudos sobre a elite eclesiástica católica (Miceli, 1988) e o modernismo literário e artístico (Miceli, 2003). Esse trabalho inaugural de análise da vida intelectual teve continuidade no plano de um projeto coletivo sobre a história das ciências sociais brasileiras, que retomaremos adiante neste artigo.

Em relação aos dois mediadores tratados acima, uma concordância entre eles deve ser ressaltada: ambos destacam a importância do livro Le métier de sociologue, de 1968 (que seria traduzido no Brasil tardiamente - Bourdieu, 1999) e a "cultura científica" que ele defendia - de entrelaçar teoria e pesquisa - e que seria incorporada por ambos fortemente, como reação à dissociação frequente de tais 230 dimensões pelos cientistas sociais brasileiros naquele momento, como ambos enfatizaram em seus depoimentos (ver também Ortiz, 2013) ${ }^{16}$.

Outros importantes mediadores nessa fase foram os sociólogos José Carlos Durand e Renato Ortiz, também voltados à sociologia da cultura, com passagem pela França e inseridos profissionalmente, respectivamente, na Fundação Getúlio Vargas e na Universidade de Campinas (Unicamp). Durand incorporou o esquema teórico de Bourdieu em quase toda a sua obra, sobretudo em sua tese de doutorado

\footnotetext{
${ }^{15}$ É interessante perceber que, ao se assumir como herdeiro principal de Bourdieu no Brasil, Miceli legitima-se também reivindicando uma independência em relação ao mestre e ao seu esquema teórico. Esse esquema interpretativo sobre a própria trajetória é reiteradamente mencionado em entrevistas e depoimentos, sendo o eixo de seu memorial de titularidade, publicado em Intelectuais à brasileira (Miceli, 2001).

${ }^{16}$ Ambos estudaram na Escola de Sociologia e Política da PUC-Rio na década de 1960 com outras figuras de destaque nas décadas seguintes. Sobre esse contexto e a relação entre os antropólogos do Museu Nacional, formados anteriormente na PUC, com a sociologia de Bourdieu, ver Keinert (2011).
} 
pioneira sobre a evolução do campo das artes e da arquitetura no Brasil (Durand, 1989), além de ter editado com Lia Machado uma coletânea de sociologia da educação que continha alguns dos primeiros textos do autor no país (Durand e Machado, 1979). A importância de Renato Ortiz no processo que estamos analisando não se deu prioritariamente por meio da mobilização direta do esquema teórico de Bourdieu em seus trabalhos ${ }^{17}$, mas, sobretudo, por organizar uma outra influente coletânea de textos (Bourdieu, 1983) na prestigiosa coleção Grandes Cientistas Sociais, coordenada por Florestan Fernandes na década de $1980^{18}$. Ortiz escreveu o estudo introdutório da coletânea, que teve também impacto como guia de leitura, como o de Miceli, sobretudo pela tentativa de elucidar as noções de habitus e campo e a empreitada de Bourdieu de superar a oposição entre estrutura e ação. Vale a pena nos referirmos à passagem inicial da apresentação de Renato Ortiz ${ }^{19}$, pois ela evidencia o estatuto da recepção de Bourdieu na fase que estamos analisando: o sociólogo francês era uma das referências contemporâneas incorporadas no período em função das transformações por que passavam as ciências sociais de então. A seguir, veremos que ele passa a ser reconhecido como um autor clássico da disciplina e como a principal referência do corpo teórico da sociologia da cultura.

\footnotetext{
${ }^{17}$ Embora isso também tenha ocorrido, não se deu de maneira tão determinante em seus trabalhos, que se apoiaram também em outras referências teóricas.

${ }^{18}$ De acordo com os depoimentos de Ortiz e Miceli aos autores, as duas coletâneas mencionadas foram constituídas por meio de negociação direta com Bourdieu, que sugeriu textos e avalizou as versões finais. Deduz-se daí que Bourdieu já se preocupava naquele momento com a divulgação internacional de seu trabalho e com a recepção específica que poderia ter nos diversos contextos nacionais. Sobre a coletânea organizada por Renato Ortiz e sobre a sua percepção acerca da recepção de Bourdieu no Brasil, ver Ortiz (2013).

19 "Organizar uma coletânea de textos de um autor contemporâneo nos coloca de imediato diante da difícil tarefa de situá-lo na corrente do pensamento sociológico moderno. Tem-se, por um lado, o reconhecimento real do valor de sua obra, mas se constata, por outro, que ele a não transformou ainda em um 'clássico', no sentido que a literatura científica confere a este termo” (Ortiz, 1983, p. 7).
} 
Um último mediador nessa fase, mas que atuaria principalmente na seguinte é Afrânio Garcia Jr. ${ }^{20}$. Doutor em antropologia social sob a orientação de Moacir Palmeira no Museu Nacional, lecionou na Universidade Federal do Rio de Janeiro (UFRJ) entre 1977 e 1998. Em 1983, realizou estágio de pós-doutorado na França ${ }^{21}$, a partir do qual ele redirecionaria sua trajetória, orientando suas pesquisas, antes focadas na questão agrária brasileira (Garcia Jr., 1983 e 1989), para a história intelectual (Garcia Jr., 1993). Do ponto de vista institucional, iniciaria na década de 1990 sua carreira como professor na École des Hautes Études en Sciences Sociales e se tornaria membro do Centre de Sociologie Européenne. Esse itinerário relaciona-se com o aspecto mais importante de sua atuação no contexto que estamos examinando: estabelecido na França, ele consolidou uma rede de relações ainda ativa, responsável por um intercâmbio permanente entre pesquisadores dos dois 232 países (cf. Lopes, 2013).

Nos anos que marcam a estreia da sociologia bourdiesiana no Brasil, portanto, o público acadêmico teve acesso a um conjunto limitado de textos em português - porém comparativamente destacado no contexto internacional (Sapiro e Bustamante, 2009) -, que permitiu uma introdução aos temas e abordagens principais de Bourdieu. As publicações mais influentes nesse momento foram coletâneas. Os livros traduzidos na íntegra - $A$ reprodução, $O$ desencantamento do mundo (tradução de Algérie 60) e Questões de sociologia - tiveram menor repercussão, com a exceção do primeiro título, na área de educação, como veremos adiante. Levando em conta outros contextos nacionais - como o dos Estados Unidos, por exemplo -, é notável a ausência da tradução de

\footnotetext{
${ }^{20}$ Sobre a atuação de outros acadêmicos nesse processo - como Maria Andrea Loyola e Roberto Grün -, ver Leite Lopes (2013).

${ }^{21}$ Neste ano, Garcia Jr. envolve-se diretamente na publicação do livro Questões de Sociologia, publicado no Brasil por sua indicação (Bourdieu, 1981).
} 
alguns títulos, sobretudo $A$ distinção, que, como veremos, só seria publicada muito tardiamente no Brasil (Bourdieu, 2007). Durante o período analisado, os textos de Bourdieu foram sendo progressivamente incorporados aos programas dos cursos de ciências sociais, sendo comuns os relatos de professores sobre o tipo de reação inicial dos alunos: em função da radicalização política do período e da voga do marxismo na academia, havia a tendência de interpretá-lo como um profeta da reprodução social inelutável e como um teórico excessivamente esquemático.

No período tratado, a recepção da obra de Bourdieu se deu, portanto, de forma circunscrita, tanto do ponto de vista da publicação de sua obra em português, como em relação à incorporação de seu esquema analítico por pesquisadores brasileiros. Quanto à sua conversão efetiva em instrumento de pesquisa no universo das ciências sociais, isso ocorre como vetor de renovação em alguns grupos e nichos temáticos da sociologia e da antropologia, notadamente, naqueles voltados ao estudo da cultura na sociedade brasileira contemporânea. Nesse sentido, ganha relevo a discussão a respeito do modo especificamente brasileiro de combinar alta e baixa cultura, produção e consumo da cultura erudita e da indústria cultural, temática explorada em profundidade na fase seguinte. Note-se, ainda, que a força inegável de sua presença não é suficiente para deslocar a perspectiva frankfurtiana dominante no período. Noutros termos, Bourdieu é um renovador, mas não ainda uma referência consolidada. Permite um arejamento dos pontos de vista, mas não se impõe como marco definitivo. Em resumo, um (importante) contemporâneo, mas ainda não um clássico.

\section{Dispersão temática e recepção ampliada de Bourdieu}

Lembrando que tomamos como marco desta última fase a ser considerada a abertura do sistema político brasileiro em 1985. Nesse período, as características centrais das ciências 
sociais no país são sua expansão ainda mais pronunciada (criação de novos cursos de graduação e programas de pós-graduação, o crescimento do número de publicações e fortalecimento das associações científicas das disciplinas), a maior profissionalização das carreiras, a especialização estrita no interior de cada uma das disciplinas e a dispersão temática correspondente. Torna-se impossível discernir desde então uma questão abrangente o suficiente para reunir as pesquisas realizadas em todo o país em torno de um eixo, como fora nos períodos anteriores em torno dos temas da modernização (fase de fundação) e democratização (fase de expansão). Dá-se, portanto, um afastamento progressivo entre tais disciplinas e as conjunturas políticas imediatas (ou um processo de "autonomização", nos termos de Bourdieu), a não ser nas especialidades diretamente referidas a tais problemas (Keinert, 2011).

Contudo, a consagração mais contundente de Bourdieu, 234 principalmente na Europa e nos Estados Unidos ${ }^{22}$, impulsionou no Brasil uma política editorial mais sistemática e abrangente, que multiplicou a publicação de seus livros, em geral acompanhando o ritmo das edições francesas, mas também trazendo versões brasileiras de obras importantes do período anterior, como A profissão de sociólogo (no Brasil em 1999, na França em 1968), O amor pela arte (2003/1966) e $A$ distinção (2007/1979). Provavelmente, tais edições tardias se deram como consequência do sucesso acadêmico e

\footnotetext{
${ }^{22}$ Desde a criação da revista Actes de la Recherche, em 1975, da publicação de $A$ distinção em 1979 e de sua posse como professor da cadeira de sociologia do Collège de France (em 1981), Bourdieu ganha uma enorme notoriedade acadêmica na França e em outros países. Sapiro e Bustamante (2009) destacam que, a partir de 1996, essa consagração ganharia outra escala, desde o momento em que ele se destaca como intelectual público, com a publicação de livros como Contrafogos e Sobre a televisão (que tiveram grande sucesso editorial em todo o mundo) e com suas intervenções políticas em apoio a movimentos sociais e em oposição ao neoliberalismo. Nessa nova fase, Bourdieu passa a ser visto internacionalmente como um autor clássico e uma espécie de celebridade acadêmica internacional.
} 
editorial de As regras da arte ${ }^{23}$. Esse livro, publicado na França em 1992 e quatro anos depois no Brasil, é o caso paradigmático da nova tendência de acompanhar mais de perto o calendário das publicações francesas, que inclui também $A$ miséria do mundo (1997/1993), Sobre a televisão (1997/1996), Meditações pascalianas (1997/1997), Contrafogos (1998/1998) e A dominação masculina (1998/1998). Nesse grupo de escritos dos anos de 1990, As regras da arte ocupou um lugar central no contexto brasileiro, seja por oferecer um modelo de análise que buscava contornar o dualismo rígido entre interpretação interna e externa da obra de arte, seja pelo rendimento empírico da aplicação cruzada das noções de campo e habitus. Posteriormente, ganharia impulso o interesse pelas incursões militantes de Bourdieu, diretamente favorecido pelos outros títulos citados. Especialmente Sobre a televisão, Contrafogos e A miséria do mundo conquistaram a simpatia de setores da intelectualidade brasileira alinhados à esquerda, anteriormente refratários à obra de Bourdieu. Esses livros também motivaram uma repercussão considerável na mídia impressa brasileira, sobretudo nos principais jornais do Rio de Janeiro e de São Paulo.

A recepção mais favorável e ampliada (em relação aos períodos anteriores) de Bourdieu vincula-se, principalmente, ao notável desenvolvimento da área da sociologia da cultura no Brasil. Uma das dimensões centrais desse movimento tem relação com os desdobramentos da atuação acadêmica de Sergio Miceli nesse novo contexto, sobretudo, em função da pesquisa que ele dirigiu no Instituto de Estudos Econômicos, Sociais e Políticos de São Paulo (Idesp) sobre a História das ciências sociais no Brasil

\footnotetext{
${ }^{23}$ A partir da publicação de As regras da arte no Brasil, em 1996, seus livros tornam-se disputados pelo mercado editorial nacional. Se Bourdieu nunca se tornou um grande sucesso comercial, a inclusão de suas obras nos catálogos de importantes editoras brasileiras (como Companhia das Letras, Zahar, Vozes e Bertrand Brasil) passou a ser vista como um sinal de prestígio inequívoco.
} 
(editada em dois volumes - Miceli, 1989 e 1995) e de seu ingresso na Universidade de São Paulo como professor ${ }^{24}$. Reunindo pesquisadores de diversas disciplinas, como as antropólogas Lilia Schwarz, Mariza Corrêa, Fernanda Peixoto e Heloísa Pontes, a socióloga Maria Arminda do Nascimento Arruda, os cientistas políticos Fernando Limongi e Maria Hermínia Tavares de Almeida -, a equipe produziu uma interpretação sobre a história das ciências sociais que se tornou obra de referência, graças ao apuro no deslindamento dos perfis institucionais, dos padrões de profissionalização da atividade acadêmica, dos embates geracionais e das lógicas internas de sociabilidade dos grupos. A despeito da heterogeneidade de formação dos participantes e das diferenças entre os textos coligidos, as análises de Bourdieu sobre o campo intelectual foram decisivas para a estruturação mais geral do trabalho, espécie de ponto de viragem se levarmos em conta que sua 236 perspectiva analítica renovadora influenciou diretamente inúmeras pesquisas realizadas posteriormente (principalmente, Arruda, 2001; Pontes, 1998; Peixoto, 2000). De modo mais geral, diríamos que a obra coletiva implica uma mudança significativa no corpo teórico dessa área específica, ocorrendo o deslocamento da vertente frankfurtiana por outra nucleada em Bourdieu, mas inspirada também em outros autores como Norbert Elias, Fritz Ringer, Raymond Williams, Carl Schorske, entre outros (cf. Arruda, 2001; Maia, 2007).

A sociologia da cultura tem sido, portanto, nas últimas décadas, a área mais importante para a assimilação no Brasil

\footnotetext{
${ }^{24}$ Em função disso, a sociologia da USP, que anteriormente havia sido refratária a Bourdieu, torna-se a instituição acadêmica central para sua recepção. Uma evidencia dessa centralidade é o grande número de referências ao sociólogo francês na revista Tempo Social (editada por esse departamento), algumas delas inscritas em artigos de herdeiros diretos de Bourdieu (por exemplo, Sapiro, 2004; e Delsaut, 2005).
} 
da sociologia de Bourdieu ${ }^{25}$. Conjugada ao maior empenho editorial em traduzir a obra do sociólogo e à mudança da imagem política de Bourdieu derivada da publicação de seus livros mais militantes, tal configuração impulsionou nos últimos anos a incorporação do autor em outras áreas, como a sociologia econômica (Grün, 2006), a sociologia da religião (Negrão, 2005), a teoria social (Vandenberghe, 2006) e os estudos de gênero (Correa, 1999) ${ }^{26}$.

\section{Estudos de classe e a recepção tardia de A distinção}

A despeito da importância da recepção de Bourdieu nas ciências sociais brasileiras nos últimos trinta anos, apenas em 2007 o livro A distinção - considerado por muitos sua obra maior - é traduzido para o português, passando a exercer desde então maior influência na produção acadêmica brasileira. Conforme mencionado anteriormente, trataremos das razões para a tradução tardia e incorporação pouco significativa do livro - questão que se justifica uma vez que foi rapidamente traduzido e teve grande repercussão em outros contextos nacionais ${ }^{27}$.

Esse "atraso" na publicação do livro pode ser explicado, em grande medida, pelas relações entre as ciências sociais no Brasil e a política, sobretudo nas décadas de 1980

\footnotetext{
${ }^{25}$ Isso não significa, entretanto, que Bourdieu seja uma referência consensual e unificadora no interior dessa área, na qual a história das ideias é muito prestigiosa e resistente às abordagens sociológicas mais estritas de inspiração bourdiesiana, defendidas no Brasil, sobretudo por Sergio Miceli (cf. Schwarz e Botelho, 2011).

${ }^{26}$ Com relação a esta última área de estudos, o livro A dominação masculina recebeu críticas substantivas por supostamente não levar em conta a bibliografia feminista consagrada sobre o tema, e, dessa forma, desqualificar o alcance político e o impacto intelectual das lutas feministas.

${ }^{27}$ Nos EUA, por exemplo, o livro é traduzido já em 1984 e, desde então, gera um significativo debate, além de ter provido o principal referencial teórico para várias análises do arranjo e das práticas de classe do país. Sapiro e Bustamante (2009) informam que o intervalo médio entre a publicação na França e a tradução dessa obra em outros países foi de quinze anos; no Brasil, apesar de sua importância relativa nessa disseminação desde os anos de 1970, A distinção levou vinte e oito anos para ser publicada.
} 
e 1990. Ao longo dos anos de 1980, durante a transição democrática, o Brasil vive um período de intensa agitação política, com a formação de novos partidos e o surgimento de uma série de novos movimentos sociais. A emergência de novas formas de protesto, a luta contra o regime militar e as novas demandas populares em voga tornam-se temas centrais para os cientistas sociais brasileiros interessados no tema das classes sociais (Paoli, Sader e Telles, 1984; Sader, 1988; Tavolaro, 2009). Nesse contexto, portanto, a temática das classes sociais torna-se extremamente politizada, voltando o foco para as relações entre os movimentos sociais e o Estado (Guimarães, 1999), o que dificultou, provavelmente, o interesse por um estudo como A distinção, cujo foco recaía na questão do consumo cultural, o que parecia naquele momento uma questão menor ${ }^{28}$.

Nos anos de 1990, no contexto da nova república, o problema das relações entre Estado e sociedade conti238 nua central, apesar das especificidades políticas da época (avanço do neoliberalismo, enfraquecimento dos movimentos sociais e emergência de novas formas de organização da sociedade civil - conforme Lavalle, Castello e Bichir, 2004). Novamente, o tema da reprodução da desigualdade por via da conformação social de padrões de gosto parecia menos premente frente aos desafios de superação de uma estrutura autoritária e do estabelecimento de uma nascente democracia.

Apenas recentemente, as pesquisas de Bourdieu nessa área influenciaram mais diretamente trabalhos de pes-

\footnotetext{
${ }^{28}$ Em outros termos, prevalecem no período análises que privilegiam a luta pela cidadania e pela democratização política - questões afinadas com a tradição da sociologia brasileira, sempre atenta às relações entre Estado e sociedade (cf. Cardoso, 1964; Werneck Vianna, 1976; Weffort, 1980). Esses estudos dos anos de 1980 e início dos anos de 1990 fundamentam-se ainda na literatura filosófica sobre a esfera pública (Habermas e Hanna Arendt), em autores franceses que discutiam o problema da democracia e dos movimentos sociais (Touraine e Lefort), e na história social inglesa (sobretudo Thompson e Hobsbawm).
} 
quisadores brasileiros, como o sociólogo Jessé Souza, que incorporou A distinção numa chave mais ampla de discussão, orientada por temas recorrentes do pensamento social brasileiro - principalmente os problemas da reprodução do autoritarismo nas relações de classe, a invisibilidade dos processos geradores de desigualdade e a permanência de formas precárias de cidadania (Souza, 2003). Além disso, Souza dirige um programa de pesquisa inspirado em $A$ miséria do mundo, centrado na análise das experiências vividas por indivíduos em situação de vulnerabilidade social (Souza, 2009), além de membros da classe trabalhadora (Souza, 2010). Em outra direção, Brasílio Sallum e alguns de seus alunos na USP têm explorado as propostas analíticas presentes em A distinção (Sallum, 2005; Pulici, 2010; Bertoncelo, 2010). O livro é referência, ainda, para uma série de pesquisas antropológicas focadas na questão da mídia e do consumo cultural (Almeida, 2003; Hamburger, 2005; Lima, 2008).

\section{Educação}

Hoje, a teoria de Bourdieu é uma das referências centrais para a pesquisa na área de educação no Brasil. Contudo, sua recepção foi igualmente obliterada, entre os anos de 1970 e início dos 1990, pela grande politização da área no país. Tal contexto implicou que, nos anos de 1980, o debate fosse dominado pela exigência de formulação de propostas práticas progressistas para a educação no país. Esse quadro representava um grande obstáculo à leitura de obras como A reprodução, que, além de apresentar um vocabulário e um método de pesquisa ainda incomuns até então, não mostrava nenhuma proposta direta de intervenção.

De acordo com A. Catani, D. B. Catani e Pereira (2001), nos anos de 1970 e 1980, a leitura de Bourdieu foi frequentemente feita a partir da cobrança de seus "pressupostos políticos". Para muitos, ele era "politicamente desmobilizador", 
sobretudo quando comparado a uma perspectiva progressista como a do pedagogo brasileiro Paulo Freire, que, bastante popular à época, era visto como mais propenso à politização e à militância (Catani, Catani e Pereira, 2001, p. 67). Na linguagem da época, Bourdieu era classificado como um "reprodutivista" pela maioria dos comentaristas, em oposição a teóricos da "transformação" ou da "resistência" 29.

Esse quadro foi mudando lentamente no final da década de 1980 e mais rapidamente ao longo da década de 1990. Isso se deveu tanto à estabilização política no país (a partir da eleição de Fernando Henrique Cardoso em 1994), como à legitimação crescente de Bourdieu em outras áreas acadêmicas e ao impulso editorial já referido. A diversificação teórica e metodológica entre estudiosos da educação, conduziu, progressivamente, à superação da dicotomia "reprodução/transformação" (A. Catani, D. B. Catani e Pereira, 2001, p. 71). Além disso, essa maior aceitação 240 de Bourdieu foi condicionada diretamente pelo esforço de pesquisadores como Afrânio Catani ${ }^{30}$, Maria Alice Nogueira e Tomaz Silva ${ }^{31}$, que publicaram trabalhos sobre a sociologia da educação de Bourdieu (por exemplo, Catani, 2002; Nogueira, 1990; Nogueira e Nogueira, 2009) e conduziram e orientaram pesquisas em que sua teoria era mobilizada para a compreensão da educação brasileira (Nogueira e Almeida, 2003) ${ }^{32}$.

\footnotetext{
${ }^{29}$ Outra forma de detratação era classificar a teoria de Bourdieu como "não dialética" - como observam A. Catani, D. B. Catani e Pereira (2001, p. 17), a maior forma de crítica política via desqualificação epistemológica. Muitos desses críticos aproximavam Bourdieu, sem maior análise dos livros, ao marxismo estruturalista de Althusser.

${ }^{30}$ Catani havia trabalhado, ainda quando estudante de graduação nos anos de 1970 na Fundação Getúlio Vargas, como assistente de pesquisa de Sergio Miceli, período em que teve o primeiro contato com as obras de Bourdieu (cf. Catani, 2002).

${ }^{31}$ Também devem ser destacados os recentes estudos sobre a educação superior brasileira inspirados por Bourdieu (Garcia, 2000; Hey, 2008).

${ }^{32}$ Cabe destacar a publicação de uma importante coletânea organizada por Catani e Nogueira com escritos de Bourdieu sobre educação (Bourdieu, 1989).
} 
Uma pequena controvérsia: o debate em torno de "Sobre as artimanhas da razão imperialista"

O tema da importação de categorias produzidas em países centrais para a compreensão das sociedades latino-americanas sempre recebeu atenção e foi alvo de críticas por sucessivas gerações de intelectuais. Essa temática se manifestou, por exemplo, no embate entre o universalismo científico de Florestan Fernandes e o nacionalismo de Guerreiro Ramos, ou na discussão provocada pelo texto de Roberto Schwarz (1977), "Ideias fora do lugar", sobre o liberalismo no Brasil do século XIX.

As discussões sobre raça e etnicidade não escaparam a essa tendência. Mais recentemente, esses debates giraram em torno da adequação de se aplicarem no Brasil medidas de ação afirmativa que, segundo seus críticos (Maggie, Fry, Maio, 2007; Fry e Maggie, 2004), levariam à imposição de um modelo racial norte-americano a uma formação social que não funcionaria a partir de um sistema classificatório dicotômico ligado à questão racial. Os intelectuais favoráveis às ações afirmativas defendem que as assimetrias entre brancos e não brancos explicariam grande parte da desigualdade e uma série de outras dimensões cotidianas de violência, mais ou menos institucionalizadas no país; nesse sentido, as ações afirmativas com recorte racial seriam uma forma, mesmo que parcial, de promoção de justiça (ver, por exemplo, Guimarães, 2005; Sansone, 1998).

É nesse contexto extremamente politizado e dividido que o artigo de Bourdieu e Wacquant, "Sobre as artimanhas da razão imperialista”, é lido. Nesse artigo, os autores criticam a imposição de um modelo binário de relações raciais ao estudo da sociedade brasileira. Essa imposição resultaria da transferência irrefletida de categorias sociológicas desenvolvidas para o contexto norte-americano ao nacional. Nesse caso, as relações raciais se conformariam de maneira mais flexível e as classificações seriam mais diversas e contextuais 
(Bourdieu e Wacquant, 2002 [1998]). Os principais responsáveis por tal imposição seriam fundações norte-americanas e acadêmicos patrocinados por elas, sejam eles americanos ou brasileiros com treinamento nos Estados Unidos ${ }^{33}$.

Essa crítica gerou respostas contundentes de acadêmicos norte-americanos (Hanchard, 2003; Telles, 2003; French, 2000) e brasileiros. Na verdade, a crítica de Bourdieu e Wacquant foi lida inicialmente com bastante estranheza no Brasil, uma vez que ela desconsiderava as especificidades e nuances do debate brasileiro sobre a questão racial, assim como a crítica nacional contínua sobre a importação de categorias. Essa resposta, elaborada, principalmente por cientistas sociais favoráveis às ações afirmativas, foi apresentada em um número especial da Revista Estudos Afro-Asiáticos, editada por Livio Sansone ${ }^{34}$. Em seu artigo, Sansone afirma o caráter transnacional da questão racial - tanto nas manifestações sociais e culturais dos atores sociais, quanto nos marcos interpreta242 tivos da academia (Sansone, 2002). Sérgio Costa argumenta que Bourdieu e Wacquant, nesse artigo, seriam eles mesmos propagadores de uma dicotomia simplista, que não refletiria a discussão sobre as relações raciais no Brasil, nem em seu conteúdo, nem em sua dinâmica transnacional (Costa, 2002) $)^{35}$.

\footnotetext{
${ }^{33}$ Os sociólogos franceses usam como principal exemplo do funcionamento dessa razão imperialista o trabalho do cientista político norte-americano Michael Hanchard sobre o movimento negro brasileiro (Hanchard, 1998), argumentando que ele transformaria o movimento por direitos civis dos Estados Unidos em modelo universal para a compreensão das lutas de todos os grupos oprimidos com base em raça ou casta, em qualquer contexto (Bourdieu e Wacquant, 1998, p. 44). A crítica a intelectuais brasileiros, por sua vez, é bastante genérica, já que eles não citam nenhum acadêmico em particular.

${ }^{34}$ Esse número da revista traz a tradução do texto de Bourdieu e Wacquant e das três principais respostas de norte-americanos àquela crítica, elaboradas por Hanchard, Telles e French, e quatro artigos de acadêmicos brasileiros (Sansone, 2002; Costa, 2002; Santos, 2002; Pinho e Figueiredo, 2002). Além disso, era para ter havido ainda uma resposta de Bourdieu e Wacquant, que foi impossibilitada pelo falecimento do primeiro durante a preparação do número.

${ }_{35}$ Assim como Hanchard, Costa ainda argumenta que haveria uma conexão entre os movimentos negro norte-americano e o brasileiro que participaria na circulação internacional desses modelos políticos e analíticos, mas que de forma alguma poderiam ser conceituados como manifestação de uma razão imperialista (Costa, 2002).
} 
Essa recepção crítica do argumento de Bourdieu e Wacquant é, certamente, um capítulo menor da recepção da obra de Bourdieu no Brasil, e não ameaçou seu prestígio no cenário intelectual brasileiro. Mas ela também demonstra como um produto intelectual que, em determinado contexto possui um caráter crítico inegável - no caso, a crítica francesa à hegemonia anglo-fônica e particularmente norte-americana nas ciências sociais internacionais ${ }^{36}$-, pode ser recebida como conservadora e imprecisa em outro contexto nacional.

\section{Contemporâneo clássico}

O Brasil esteve entre os primeiros países a incorporar os trabalhos de Bourdieu e seria, até os dias atuais, um dos casos centrais dessa recepção (Sapiro e Bustamante, 2009). No momento em que se inicia sua leitura pelas ciências sociais brasileiras, no final da década de 1960, esse processo beneficia-se da cultura acadêmica preexistente, caracterizada pela valorização da sociologia como ciência, pela constituição dos primórdios de uma sociologia da cultura e pelo legado intelectual da missão francesa, que favoreceu a recepção de trabalhos produzidos na França.

Seria, entretanto, no período de expansão das ciências sociais no Brasil (1964-1985) e de transformação dessas disciplinas, em especial a partir da década de 1970, que a obra desse autor iniciaria um processo de difusão no país, diretamente dependente das iniciativas de mediadores como Moacir Palmeira, Sergio Miceli, Renato Ortiz, José Carlos Durand, José Sérgio Leite Lopes e Afrânio Garcia (entre outros). Tal movimento foi favorecido pelo incentivo público e privado à circulação internacional de jovens pesquisadores brasileiros, típico daquele momento. Isso levou à criação de laços de sociabilidade envolvendo, obviamente de forma assimétrica, acadêmicos brasileiros e franceses - muitos dos

\footnotetext{
${ }^{36}$ Como observa Livio Sansone em entrevista a nós concedida.
} 
quais persistentes até os dias atuais e decisivos tanto para a disseminação de Bourdieu e de seu grupo no Brasil, quanto para a consagração acadêmica dos brasileiros. Todos os mediadores ocupavam posições relativamente distanciadas do centro das ciências sociais brasileiras de então. Isso significa que a Universidade de São Paulo (principal núcleo irradiador da institucionalização da sociologia nacional) não foi a porta de entrada para o sociólogo francês no país, que penetrou pelas margens do sistema.

A última fase de sua recepção no Brasil, posterior à abertura política, relaciona-se diretamente à divulgação de suas obras mais militantes, que inverteram, em grande medida, a inclinação anterior de boa parte da intelectualidade brasileira de considerá-lo um autor conservador. Tais livros também o tornaram uma figura muito conhecida e divulgada pela grande imprensa.

No âmbito acadêmico, sua incorporação mais efetiva se deu 244 na área de sociologia da cultura - em grande medida devido à atuação de Sergio Miceli -, o que ajuda a explicar o sucesso de um livro como As regras da arte. Nas duas últimas décadas, muitos livros de Bourdieu foram publicados no país, reduzindo-se o intervalo entre as datas de publicação na França e no Brasil. Uma ausência significativa, apenas recentemente suprida, refere-se à tardia publicação e repercussão no país do livro A distinção - o que, até hoje, dá o tom da leitura brasileira de Bourdieu como sendo, antes de tudo, um sociólogo da cultura. Esse maior dinamismo editorial condiciona a transformação de Bourdieu em um autor fundamental para uma diversidade de áreas de pesquisa nas humanidades e ciências sociais. Inicialmente recebido como um dos autores contemporâneos mais propensos à renovação teórica e metodológica das ciências sociais, e incorporado efetivamente de forma restrita, seria reconhecido, a partir da década de 1990, como um clássico, ou seja como um interlocutor permanente, seja para os que fazem uso de suas ferramentas analíticas, seja para os que as recusam. 


\section{Quadro}

Principais mediadores da recepção da obra de Pierre Bourdieu no Brasil

\begin{tabular}{|c|c|}
\hline \multicolumn{2}{|r|}{ Moacir Palmeira } \\
\hline Nascimento & Maceió, 1942 \\
\hline Formação & $\begin{array}{l}\text { Graduação: ciências políticas e sociais (PUC-Rio); } \\
\text { doutorado: ciências humanas (Université René } \\
\text { Descartes) }\end{array}$ \\
\hline Disciplina (e linhas de pesquisa) & Antropologia (campesinato; política) \\
\hline Período na França & 1966-1969; 1997 \\
\hline Carreira (principais instituições) & Museu Nacional/UFRJ \\
\hline Publicações na Actes & - \\
\hline Atividade editorial & Texto em coletânea (Bourdieu, 1968) \\
\hline \multicolumn{2}{|r|}{ Sergio Miceli } \\
\hline Nascimento & Rio de Janeiro, 1945 \\
\hline Formação & $\begin{array}{l}\text { Graduação: ciências políticas e sociais (PUC-RJ); } \\
\text { mestrado: sociologia (USP); doutorado: sociologia (USP } \\
\text { e EHESS) }\end{array}$ \\
\hline Disciplina (e linhas de pesquisa) & Sociologia (cultura) \\
\hline Período na França & 1974-1978 \\
\hline Carreira (principais instituições) & FGV-SP; Unicamp; USP \\
\hline Publicações na Actes & $2(1975$ e 2007) \\
\hline Atividade editorial & Coletânea (Bourdieu, 1974) \\
\hline \multicolumn{2}{|r|}{ José Carlos Durand } \\
\hline Nascimento & São Paulo, 1941 \\
\hline Formação & $\begin{array}{l}\text { Graduação: ciências sociais (USP); mestrado e } \\
\text { doutorado: sociologia (USP) }\end{array}$ \\
\hline Disciplina (e linhas de pesquisa) & Sociologia (cultura) \\
\hline Período na França & 1986-1988 \\
\hline Carreira (principais instituições) & FGV-SP \\
\hline Publicações na Actes & $1(1991)$ \\
\hline Atividade editorial & Textos em coletânea (Durand e Machado, 1978) \\
\hline
\end{tabular}




\begin{tabular}{|c|c|}
\hline \multicolumn{2}{|r|}{ Afrânio Garcia } \\
\hline Nascimento & $?$ \\
\hline Formação & $\begin{array}{l}\text { Graduação: economia (PUC-RJ); mestrado e doutorado: } \\
\text { antropologia (Museu Nacional/UFRJ) }\end{array}$ \\
\hline Disciplina (e linhas de pesquisa) & Antropologia (campesinato; intelectuais) \\
\hline Período na França & 1966-1968; 1983; 1992; 1996-? \\
\hline Carreira (principais instituições) & UFRJ; EHESS \\
\hline Publicações na Actes & $4(1986,1993,1998$ e 2011$)$ \\
\hline Atividade editorial & Indicação de publicação (Bourdieu, 1981) \\
\hline \multicolumn{2}{|r|}{ Renato Ortiz } \\
\hline Nascimento & Ribeirão Preto, 1947 \\
\hline Formação & $\begin{array}{l}\text { Graduação: sociologia (Université de Paris VIII); } \\
\text { mestrado e doutorado: sociologia (EHESS) }\end{array}$ \\
\hline Disciplina (e linhas de pesquisa) & Sociologia (cultura) \\
\hline Período na França & 1970-1975; 1994-1995 \\
\hline Carreira (principais instituições) & Unicamp \\
\hline Publicações na Actes & - \\
\hline Atividade editorial & Coletânea (Bourdieu, 1983) \\
\hline \multicolumn{2}{|r|}{ Afrânio Catani } \\
\hline Nascimento & Campinas, 1953 \\
\hline Formação & $\begin{array}{l}\text { Graduação: administração (FGV-SP); mestrado e } \\
\text { doutorado: sociologia (USP) }\end{array}$ \\
\hline Disciplina (e linhas de pesquisa) & Sociologia (educação) \\
\hline Período na França & 1994 e 2011 \\
\hline Carreira (principais instituições) & USP \\
\hline Publicações na Actes & - \\
\hline Atividade editorial & Coletânea (Bourdieu, 1989) \\
\hline \multicolumn{2}{|r|}{ José S. Leite Lopes } \\
\hline Nascimento & Rio de Janeiro, 1947 \\
\hline Formação & $\begin{array}{l}\text { Graduação: economia (PUC-RJ); mestrado e doutorado: } \\
\text { antropologia (Museu Nacional/UFRJ) }\end{array}$ \\
\hline Disciplina (e linhas de pesquisa) & Antropologia (cidades; trabalho) \\
\hline Período na França & 1966-1968; 1988-1990 \\
\hline Carreira (principais instituiç̧ões) & Museu Nacional/UFRJ \\
\hline Publicações na Actes & $3(1989,1990$ e 1994$)$ \\
\hline Atividade editorial & - \\
\hline
\end{tabular}




\section{José Henrique Bortoluci}

é doutorando em Sociologia na Universidade de Michigan (Bolsa Capes-Fulbright) e professor do CPDOC, Fundação Getúlio Vargas (FGV-SP).

\section{Luiz Carlos Jackson}

é professor do Departamento de Sociologia da Universidade de São Paulo e pesquisador do CNPq.

\section{Fernando Antonio Pinheiro Filho}

é professor do Departamento de Sociologia da Universidade de São Paulo e pesquisador do CNPq.

\section{Bibliografia}

\section{Principais trabalhos de Bourdieu publicados no Brasil}

1968. "Campo intelectual e projeto criador". In: POUILLON, J. (org.).

Problemas do estruturalismo. Rio de Janeiro: Zahar.

1974. A economia das trocas simbólicas. São Paulo: Perspectiva. [coletânea;

ed.: S. Miceli].

1975. A reprodução: elementos para uma teoria do sistema de ensino. Rio

de Janeiro: Francisco Alves. [com J.-C. Passeron] .

1979. Educação e hegemonia de classe. Rio de Janeiro: Zahar. [orgs.: J. C.

Durand e L. Z. Machado].

1979. O desencantamento do mundo: estruturas econômicas e estruturas

sociais. São Paulo: Perspectiva.

1981. Questões de sociologia. Rio de Janeiro: Marco Zero.

1983. Pierre Bourdieu: Sociologia. São Paulo: Ática (coleção Grandes

Cientistas Sociais). [ed.: R. Ortiz].

1988. Lições da aula. São Paulo: Ática.

1989. O poder simbólico. Rio de Janeiro: Bertrand Brasil.

1989. A ontologia política de Martin Heidegger. Campinas, SP: Papirus.

1989. Escritos de educação. Petrópolis, RJ: Vozes. [eds.: M. A. Nogueira e A.

Catani].

1990. Coisas ditas. São Paulo: Brasiliense.

1995. Livre troca: diálogos entre ciência e arte. Rio de Janeiro: Bertrand Brasil. 1996. A economia das trocas linguísticas: o que falar quer dizer. São Paulo:

Edusp. 
1996. As regras da arte: gênese e estrutura do campo literário. São Paulo:

Companhia das Letras.

1996. Razões práticas: sobre a teoria da ação. Campinas, SP: Papirus.

1997. Sobre a televisão. Rio de Janeiro: Jorge Zahar.

1997. A miséria do mundo. Petrópolis, RJ: Vozes.

1997. Meditações pascalianas. Rio de Janeiro: Bertrand Brasil.

1998. Contrafogos 1 : táticas para enfrentar a invasão neoliberal. Rio de

Janeiro: Jorge Zahar.

1999. A dominação masculina. Rio de Janeiro: Bertrand Brasil.

1999. A profissão de sociólogo: preliminares epistemológicas. Petrópolis, RJ:

Vozes. [com J.-C. Chamboredon e J.-C. Passeron].

2000. O campo econômico: a dimensão simbólica da dominação. Campinas,

SP: Papirus.

2001. Contrafogos 2 : por um movimento social europeu. Rio de Janeiro:

Jorge Zahar

2002. A produção da crença: contribuição para uma economia dos bens

simbólicos. São Paulo: Zouk.

2002. "Sobre as artimanhas da razão imperialista". Estudos Afro-Asiáticos,

v. 24, n. 1, pp. 15-33. [com L. Wacquant].

$248 \quad$ Paulo: Edusp/Zouk.

2003. Os usos sociais da ciência - por uma sociologia clínica do campo

científico. São Paulo: Ed. Unesp.

2007. A distinção: crítica social do julgamento. São Paulo: Edusp/Zouk.

2009. O senso prático. Petrópolis, RJ: Vozes.

2010. Esboço de autoanálise. São Paulo: Companhia das Letras.

2011. Homo academicus. Florianópolis: Ed. UFSC.

\section{Demais trabalhos citados}

ALMEIDA, H. B. de (2003). Telenovela, consumo e gênero. Bauru, SP: Edusc/ Anpocs.

ALMEIDA, M. H. T. 1987. "Castelos na areia: dilemas da institucionalização das ciências sociais no Rio de Janeiro”. BIB, n. 24, pp. 41-60.

ARRUDA, M. A. do N. 2001. "Trajetórias da sociologia da cultura no Brasil: os anos recentes”. Revista USP, n. 50, pp. 100-07. 2011. Metrópole e cultura em São Paulo no século XX. Bauru, SP:

Edusc.

BASTOS, E. R.; BOTELHO, A. (2010). "Para uma sociologia dos intelectuais". Dados, v. 53, n. 4. 
BASTOS, E. et al. 2006. Conversas com sociólogos brasileiros. São Paulo: Editora 34.

BERTONCELO, E. R. E. 2010. Classes sociais e estilo de vida na sociedade brasileira. Tese de doutorado em Sociologia. São Paulo: USP.

BOURDIEU, P.; WACQUANT, L. 1998. "Sur les ruses de la raison impérialiste". Actes de la recherche en sciences sociales, n. 121, pp. 109-18.

CARDOSO, F. H. 1964. Empresário industrial e desenvolvimento econômico no Brasil. São Paulo: Difusão Europeia do Livro.

CATANI, A. M. 2002. "A sociologia de Pierre Bourdieu (ou como um autor se torna indispensável ao nosso regime de leituras)". Educação $e$ Sociedade, Campinas, v. XXIII, n.78, pp. 57-75.

CATANI, A.; CATANI, D. B.; PEREIRA, G. R. M. 2001. “As apropriações da obra de Pierre Bourdieu no campo educacional brasileiro, através de periódicos da área”. Revista Brasileira de Educação, n. 17, pp. 63-85.

CORREA, M. 1999. "Bourdieu e o sexo da dominação". Novos Estudos Cebrap, n. 54.

COSTA, S. 2002. "A construção sociológica da raça no Brasil”. Estudos AfroAsiáticos, v. 24, n. 1, pp. 35-61.

DELSAUT, Y. 2005. "Depoimento sobre Les Héritiers". Tempo Social, v. 17, n. 1, pp. 211-28.

DURAND, J. C. 1989. Arte, privilégio e distinção: artes plásticas, arquitetura e classe dirigente no Brasil, 1855-1985. São Paulo: Perspectiva.

1991. "Négociation politique et rénovation de l'architecture". Actes de la Recherche en Sciences Sociales, n. 88.

DURAND, J. C.; MACHADO, L. Z. (orgs.). 1979. Educação e hegemonia de classe. Rio de Janeiro: Zahar.

FRENCH, J. D. 2000. "The missteps of anti-imperialist reason: Bourdieu, Wacquant, and Hanchard's Orpheus and power". Theory, Culture and Society, v. 17, n. 1, pp.107-28.

FRY, P. H.; MAGGIE, Y. 2004. "A reserva de vagas para negros nas universidades brasileiras”. Estudos Avançados, v. 18, n. 50, pp. 67-80.

GARCIA Jr., A. 1983. Terra de trabalho: trabalho familiar de pequenos produtores. Rio de Janeiro: Paz e Terra.

. 1986. "Libres et assujettis". Actes de la Recherche en Sciences Sociales, n. 65. 1989. O Sul: caminho do roçado. Estratégias de reprodução camponesa e transformação social. São Paulo: Marco Zero/CNPq/UnB. 1993. "Les intellectuels et la conscience nationale au Brésil". Actes de la Recherche en Sciences Sociales, n. 98.

. 1998. "La construction interrompue". Actes de la Recherche en Sciences Sociales, n. 121-22. 
2011. "Les souvenirs d'un européen: entre le Brésil, terre d'avenir et le monde d'hier”. Actes de la Recherche en Sciences Sociales, n. 186-187.

GARCIA, S. G. 2000. "A questão da universidade e da formação em ciências sociais”. Tempo Social, v. 12, n. 1, pp. 123-40.

GRÜN, R. 2006. Os caminhos da sociologia econômica no Brasil. In: I CONGRESSO INTERNACIONAL DE SOCIOLOGIA ECONÔMICA E DAS FINANÇAS, São Carlos, SP.

GUIMARÃES, A. S. A. 1999. "Classes sociais". In: MICELI, S. (org.). O que ler na ciência social brasileira. São Paulo: Ed. Sumaré.

2005. Racismo e antirracismo no Brasil. 2. ed. São Paulo: Editora 34.

GURZA LAVALLE, A.; CASTELLO, G.; BICHIR, M. R. 2004. “Quando novos atores saem de cena - continuidades e mudanças na centralidade dos movimentos sociais". Política Ẽ Sociedade, Florianópolis, v. 5, n. 2, pp. 35-54.

HAMBURGER, E. 2005. O Brasil antenado: a sociedade da novela. Rio de Janeiro, Zahar.

HANCHARD, M. 1998. Orpheus and power. Princeton, NJ: Princeton University Press.

2003. "Acts of misrecognition: transnational black politics, antiimperialism and the ethnocentrisms of Pierre Bourdieu and Loïc Wacquant”. Theory, Culture E Society, v. 20, n. 4, pp. 5-29.

250 HEINICH, N. 2001. La sociologie de l'art. Paris: La Découverte

HEY, A. P. 2008. Esboço de uma sociologia do campo acadêmico. A educação superior no Brasil. São Carlos: EdUFSCar.

JACKSON, L. C.; BLANCO, A. 2014. Sociologia no espelho: ensaístas, cientistas sociais e críticos literários no Brasil e na Argentina (19301970). São Paulo: Editora 34.

KEINERT, F. C. 2011. Instituições e novas linhas de força: a produção da sociologia no Brasil nas décadas de 1970 e 1980. Tese de doutorado em Sociologia. São Paulo: USP.

LEITE, A. N. 2014. Milagre acadêmico: a institucionalização das ciências sociais brasileiras (1964-1985). Dissertação de mestrado em Sociologia. São Paulo: USP.

LIMA, D. N. de O. 2008. Sujeitos e objetos do sucesso: antropologia do Brasil emergente. Rio de Janeiro: Garamond.

LIMA, N. T. 1999. Um sertão chamado Brasil: intelectuais e representação geográfica da identidade nacional. Rio de Janeiro: Revan.

LOPES, J. S. L. 1976. O vapor do diabo: o trabalho dos operários do açúcar. Rio de Janeiro: Paz e Terra.

2003 "A recepção dos trabalhos de Pierre Bourdieu e a renovação das análises sobre as classes populares brasileiras”. Cultura Vozes, Petrópolis, RJ, v. 4, n. 97, pp. 5-21. 
2013. "Touraine e Bourdieu nas ciências sociais brasileiras, duas recepções diferenciadas”. Sociologia E Antropologia, n. 3, pp. 43-79.

LOPES, J. S. L.; ALVIM, R. 1990. "Familles ouvrières, familles d'ouvrières". Actes de la Recherche en Sciences Sociales, n. 84.

LOPES, J. S. L.; FAGUER, J. 1994. "L'invention du style brésilien”. Actes de la Recherche en Sciences Sociales, n. 103.

LOPES, J. S. L.; MARESCA, S. 1989. "La disparition de 'la joie du peuple"”. Actes de la Recherche en Sciences Sociales, n. 79.

LOUREIRO, M. R. 1995. "L'Ascension des économistes au Brésil”. Actes de la Recherche en Sciences Sociales, n. 108.

1998. "L'Internationalisation des milieux dirigeants au Brésil". Actes de la Recherche en Sciences Sociales, n. 121-122.

LOYOLA, M. A. 1982. "Cure des corps et cure des âmes". Actes de la Recherche en Sciences Sociales, n. 43.

MAGGIE, Y.; FRY, P.; MAIO, M. C. (orgs.). 2007. Divisões perigosas: políticas raciais no brasil contemporâneo. Rio de Janeiro: Civilização Brasileira.

MAIA, J. M. E. 2007. "Ideias, intelectuais, textos e contextos: novamente a sociologia da cultura”. BIB, v. 41, pp. 53-72.

MICELI, S. 1972. A noite da madrinha. São Paulo: Perspectiva. . 1975. "Division du travail entre les sexes et division du travail de domination”. Actes de la Recherche en Sciences Sociales, n. 5. . 1988. A elite eclesiástica brasileira (1890-1930). Rio de Janeiro:

Bertrand-Brasil. . 1989. História das ciências sociais no Brasil. v. 1. São Paulo: Vértice/ Idesp/Finep. . 1995. História das ciências sociais no Brasil. v. 2. São Paulo: Vértice/ Idesp/Finep. . 2001. Intelectuais à brasileira. São Paulo: Cia. das Letras. . 2003. Nacional estrangeiro, história social e cultural do modernismo artístico em São Paulo. São Paulo: Cia. das Letras.

. 2007. "Jorge Luis Borges, histoire sociale d'un 'écrivain-né'”. Actes de la Recherche en Sciences Sociales, n. 168.

NEGRÃO, L. N. 2005. “Nem 'jardim encantado', nem 'clube dos intelectuais desencantados'”. RBCS, v. 20, n. 59, pp. 23-36.

NOGUEIRA, M. A. 1990. "A sociologia da educação no final dos anos 60/ início dos anos 70: o nascimento do paradigma da reprodução”. Em Aberto, n. 46, pp. 49-58.

NOGUEIRA, M. A.; ALMEIDA, A. M. (orgs.). 2002. A escolarização das elites. Petrópolis, RJ: Vozes. 
NOGUEIRA, M. A.; NOGUEIRA, C. M. M. 2009. Bourdieu Eं a educação.

3. ed. Belo Horizonte: Autêntica.

OLIVEIRA, L. L. 1995. "As ciências sociais no Rio de Janeiro". In: MICELI,

S. (org.). História das ciências sociais no Brasil. v. 2. São Paulo: Ed.

Sumaré/Idesp/Fapesp.

ORTIZ, R. 1990. "Impressões sobre as ciências sociais no Brasil”. Estudos

Cebrap, n. 27.

. 2013. "Nota sobre a recepção de Pierre Bourdieu no Brasil".

Sociologia Eै Antropologia, v. 3, pp. 81-90.

ORTIZ, R. (ed.). 1983. Pierre Bourdieu: Sociologia. São Paulo: Ática

(coleção Grandes Cientistas Sociais).

PALMEIRA, M. 1971. Latifundium et capitalisme au Brésil: lecture critique

d'un débat. Tese de doutorado em Ciências Humanas. Paris: Université René Descartes.

PAOLI, M. C., SADER, E.; TELLES, V. S. 1984. "Pensando a classe operária: os trabalhadores no imaginário acadêmico". Revista Brasileira de História, n. 1.

PEIXOTO, F. A. 2000. Diálogos brasileiros: uma análise da obra de Roger Bastide. São Paulo: Edusp/Fapesp.

PINHEIRO Filho, F. A. 2009. "The renovation: aspects of Pierre

Bourdieu's reception in Brazil”. Sociologica, n. 1, pp. 1-18.

PINHO, O. de A.; FIGUEIREDO, A. 2002. "Ideias fora do lugar e o lugar do negro nas ciências sociais brasileiras”. Estudos Afro-Asiáticos, v. 24, n. 1, pp. 189-210.

PINTO, L. 2000. Pierre Bourdieu e a teoria do mundo social. Rio de Janeiro: Ed. FGV. 2009. "Não multiplicar o indivíduo inutilmente". Lua Nova, n. 77, pp. 205-25.

PONTES, H. 1998. Destinos mistos: os críticos do Grupo Clima em São Paulo, 1940-68. São Paulo: Companhia das Letras.

PULICI, C. 2010. O charme (in)discreto do gosto burguês paulista: estudo sociológico da distinção social em São Paulo. Tese de doutorado em Sociologia. São Paulo: USP.

RODRIGUES, A. M. 1988. "Pratiques et représentations des petits fonctionnaires administratifs à São Paulo”. Actes de la Recherche en Sciences Sociales, 73.

SADER, E. 1988. Quando novos personagens entraram em cena. Rio de Janeiro: Paz e Terra.

SALLUM Jr., B. 2005. "Classes, cultura e ação coletiva”. Lua Nova, n. 65 . 
SANSONE, L. 1998. "Racismo sem etnicidade. Políticas públicas e discriminação racial em perspectiva comparada”. Dados, v. 41, n. 4, pp. 751-84.

2002. "Um campo saturado de tensões: o estudo das relações raciais e das culturas negras no Brasil”. Estudos Afro-Asiáticos, v. 24, n. 1, pp. 5-14.

SANTOS, J. T. dos. 2002. "De armadilhas, convicções e dissensões: as relações raciais como efeito orloff”. Estudos Afro-Asiáticos, v. 24, n. 1, pp. 167-87.

SAPIRO, G. 2004. "Elementos para uma história do processo de autonomização”. Tempo Social, v. 16, n. 1, pp. 93-105.

SAPIRO, G.; BUSTAMANTE, M. 2009. "Translation as a measure of international consecration: mapping the world distribution of Bourdieu's Books in translation”. Sociologica, n. 2-3, pp. 1-45.

SCHWARCZ, L. K. M.; BOTELHO, A. 2011. "Simpósio: cinco questões sobre o pensamento social brasileiro". Lua Nova, n. 82, pp. 139-59.

SCHWARZ, R. (2000) [1977]. "Ideias fora do lugar". In: Ao vencedor as batatas: forma literária e processo social nos inícios do romance brasileiro. São Paulo: Editora 34/Duas Cidades.

SIGAUD, L. 1979. Os clandestinos e os direitos: estudos sobre trabalhadores da cana de açúcar pernambucanos. São Paulo: Duas Cidades.

SOUZA, J. 2003. A construção social da subcidadania: para uma sociologia política da modernidade periférica. Belo Horizonte: Ed. UFMG. 2009. A ralé brasileira: quem é e como vive. Rio de Janeiro: Record. 2010. Os batalhadores brasileiros: nova classe média ou nova classe trabalhadora?. Belo Horizonte: Ed. UFMG.

TAVOLARO, S. B. F. 2009. "Para além de uma 'cidadania à brasileira': uma consideração crítica da produção sociológica nacional”. Revista de Sociologia e Política, v. 17, pp. 95-120.

TELLES, E. E. 2003. "US Foundations and racial reasoning in Brazil". Theory, Culture and Society, v. 20, n. 4, pp. 31-48.

VANDENBERGHE, F. 2006. "Construção e crítica na nova sociologia francesa”. Sociedade e Estado, v. 21, n. 2, pp. 315-66.

VASCONCELLOS, M. D. 1998. "L'Internationalisation des écoles de gestion au Brésil”. Actes de la Recherche en Sciences Sociales, n. 121-22.

VIANNA, L. W. 2004. A revolução passiva: iberismo e americanismo no Brasil. Rio de Janeiro: Revan.

WACQUANT, L. 1997. "Durkheim e Bourdieu: a base comum de suas fissuras". Novos Estudos Cebrap, n. 48, pp. 29-38. . 2006. "Seguindo Pierre Bourdieu no campo". Revista de Sociologia e Política, n. 26, pp. 13-29. 
WERNECK VIANNA, L. J. 1976. Liberalismo e sindicato no Brasil. Rio de Janeiro: Paz e Terra.

WEFFORT, F. 1980. O populismo na política brasileira. Rio de Janeiro: Paz e Terra.

\section{Entrevistas realizadas}

Afrânio Catani (20/5/2012)

Brasílio Sallum $(7 / 5 / 2012)$

Jessé Souza $(2 / 5 / 2012)$

José Carlos Durand (5/4/2012)

Lilia Schwarz $(8 / 5 / 2012)$

Livio Sansone $(19 / 5 / 2012)$

Marcelo Ridenti (23/4/2012)

Maria Arminda do Nascimento Arruda (24/4/2012)

Moacir Palmeira (14/5/2012)

Renato Ortiz (11/5/2012)

Sergio Miceli (10/5/2012) 


\title{
CONTEMPORÂNEO CLÁSSICO: A RECEPÇÃO DE PIERRE BOURDIEU NO BRASIL
}

\author{
JOSÉ HENRIQUE BORTOLUCI \\ LUIZ C. JACKSON \\ FERNANDO A. PINHEIRO FILHO
}

Resumo: O Brasil foi um dos casos pioneiros na recepção internacional de Pierre Bourdieu, sociólogo que, desde a década de 1990, tornou-se um dos mais citados em todo o país. Essa questão é discutida articulando-se duas séries históricas: a produção e consagração da obra de Bourdieu a partir da França e a dinâmica da institucionalização das ciências sociais no Brasil. Desde o final dos anos de 1960, a circulação de pesquisadores brasileiros na França aumentou consideravelmente, e alguns deles se constituíram em importantes mediadores da recepção de Bourdieu no Brasil; suas trajetórias e os papéis desempenhados são avaliados neste artigo. Inicialmente recebido como um dos autores contemporâneos mais propensos à renovação teórica e metodológica das ciências sociais nas décadas de 1970/80, o autor seria instituído, a partir da década de 1990, como referência obrigatória, a despeito das resistências que suscitou.

Palavras-chave: Pierre Bourdieu; História das Ciências Sociais; Sociologia dos Intelectuais; Sociologia da Cultura.

\section{CLASSIC CONTEMIPORARY: THE RECEPTION OF PIERRE BOURDIEU IN BRAZIL}

Abstract: Brazil was one of the first cases of the international reception of Pierre Bourdieu, who is one of the most cited sociologists in the country since the 1990s. This reception is discussed here along two historical lines: the production and consecration of Bourdieu's work in France, and the dynamics of institutionalization of Social Sciences in Brazil. Beginning in the late 1960s, the circulation of Brazilian researchers in France increased considerably, and some of them 
later became important mediators in the reception of Bourdieu in Brazil. Their trajectories and their roles are analyzed in this article. Initially incorporated as one of the main sources of theoretical and methodological renewal in the Social Sciences during the 1970s and 1980s, Bourdieu would become a primary reference in the 1990s, despite the resistance that his work also faced in Brazil.

Keywords: Pierre Bourdieu; History of the Social Sciences; Sociology of Intellectuals; Sociology of Culture.

Recebido: 03/11/2014Ａprovado: 20/02/2015 